\title{
Research Article \\ Realized Jump Risk and Equity Return in China
}

\author{
Guojin Chen, ${ }^{1}$ Xiaoqun Liu, ${ }^{2}$ Peilin Hsieh, ${ }^{1}$ and Xiangqin Zhao $^{2}$ \\ ${ }^{1}$ School of Economics and The Wang Yanan Institute for Studies in Economics, Xiamen University, Xiamen, Fujian 361005, China \\ ${ }^{2}$ School of Economics, Xiamen University, Xiamen, Fujian 361005, China \\ Correspondence should be addressed to Peilin Hsieh; peilin.h@gmail.com
}

Received 2 March 2014; Revised 10 May 2014; Accepted 11 May 2014; Published 23 June 2014

Academic Editor: Fenghua Wen

Copyright (C) 2014 Guojin Chen et al. This is an open access article distributed under the Creative Commons Attribution License, which permits unrestricted use, distribution, and reproduction in any medium, provided the original work is properly cited.

\begin{abstract}
We utilize the realized jump components to explore a new jump (including nonsystematic jump and systematic jump) risk factor model. After estimating daily realized jumps from high-frequency transaction data of the Chinese A-share stocks, we calculate monthly jump size, monthly jump standard deviation, and monthly jump arrival rate and then use those monthly jump factors to explain the return of the following month. Our empirical results show that the jump tail risk can explain the equity return. For the large capital-size stocks, large cap stock portfolios, and index, one-month lagged jump risk factor significantly explains the asset return variation. Our results remain the same even when we add the size and value factors in the robustness tests.
\end{abstract}

\section{Introduction}

Jump is a source which attributes to the fat tail of a return distribution. If a market is incomplete and thus investors cannot form a market portfolio to diversify the nonsystematic risk away, firm-specific and industry-level risk may have the influence over return premium and affect asset prices, making the classical capital asset pricing model (CAPM) unable to explain the returns as perfectly as the theory says. Inspired by this idea, this paper considers the jump, the tail risk, and a good supplemental factor to explain the asset returns.

After CAPM model was proposed, how well this model performs has been always challenged. Fama and French $[1,2]$ demonstrate that the CAPM model is unable to explain crosssectional stock returns well and find that value premium (HML) and size (SMB) factors outperform the market model. As a result, they proposed the well-known Fama-French three-factor model which subsequently was extended to the models with liquidity and momentum factors. Further, Harvey and Siddique [3] and Wen and Yang [4] argue that conditional coskewness, which could capture similar information contained in the size and book-to-market ratio, complements market beta to explain the return. Merton [5] also supplements a theoretical argument to market model. As CAPM model does not price idiosyncratic risk (IV), he claims that incomplete information, which hinders the investors to diversify their portfolios, leads to the positive relation between idiosyncratic risk and expected stock return.

According to the studies, the empirical results of crosssectional relation between the idiosyncratic volatility and expected return are mixed. Ang et al. [6] show that high idiosyncratic volatility in one lagged month predicts abysmally low average returns in the next month. Similarly, Guo and Robert [7] propose that, in addition to stock market volatility, the aggregate idiosyncratic volatility (IV) could be the source of risk that determines the equity return. In their preposition, IV may be considered as a proxy for variance of the risk factors of a multiple-factor or intertemporal capital asset pricing model (ICAPM). Guo and Robert [8] further used the average idiosyncratic volatility (AV-IV) as proxy for investment opportunity cost on G7 countries and concluded that IV contributes, as well as the book-to-market factor, to explaining the cross-sectional stock returns. In addition to empirical works, Campbell et al. [9] also provide a very noticeable argument for the declining explanatory power of traditional market model. In their paper, they find the increase of firm-level volatility level and market volatility level, making correlations between the stock returns lower and diversification difficult. Therefore, seeking firm-specific or aggregate level risk factors becomes a more important issue for asset pricing. 
Recently, several studies have presented the empirical evidence in favor of jump risk effects on financial asset prices by using nonparametric method and high-frequency database. Since the realized volatility (RV), the realized range volatility (RRV), and realized jump volatility (RJV) were proposed, those nonparametric measures have been applied extensively, even for the researches in volatility parametric models, for example, GARCH-RV and the heterogeneous autoregressive with realized volatility (HAR-RV) model. Those nonparametric measures not only can be used to depict the volatility dynamic nature, such as clustering, long memory, asymmetric leverage effect, and the pricevolume relation in financial market microstructure theory [10-18], but also can be considered as the risk indications. Therefore, investigating those risks' influences on asset pricing is of great interest. Adrian and Rosenberg [19] explore a new three-factor pricing model, including the long-run volatility component, the short-run volatility component, and the market return, and they conclude that their model outperforms the Fama-French model through reducing the pricing biased errors. Apparently, volatility can be a risk factor which accounts the return premium. Following Adrian and Rosenberg [19], Kelly and Jiang [20] develop a tail risk factor model. Both models are based on the structural model by theoretical derivation with explicit economical meanings. For tail risk model by Kelly, the bivariate calibration of tail risk factors with macrovariables can be based on the long-run risk model proposed by Bansal and Yaron [21] and the disaster risk model proposed by Rietz [22] and Barro [23].

Though there are a large number of researches seeking different risk factors for the returns, all of them focus on the returns of index, bond market, and credit spread. Moreover, most of those works are using high-frequency data in the United States. Inspired by those works, we propose a jumpbased model to examine the relations between the realized jump components and equity returns at China market. We will begin with an illustration of the nonparametric jump estimation method. After daily realized jump volatility is estimated from 5-minute high-frequency trading data, we then calculate monthly jump size, jump standard deviation, and jump arrival intensity. Finally, these jump components are used to investigate their predicting and explaining power over one-month-ahead equity return.

The remaining parts of this paper are organized as follows. Section 2 introduces the identification method for the highfrequency realized jump and presents the jump risk factor model, and Section 3 describes our sample data and its descriptive statistics. Empirical results are demonstrated in Section 4, and Section 5 is robustness tests analysis. Finally, the conclusion is in Section 6.

\section{Preliminaries and Theories}

2.1. Realized Jump Risk. While jumps are known to be very crucial in the asset pricing [32], estimation of jump components by parametric model has been questioned for the stability over different sample time periods. With the availability of high-frequency data, nonparametric estimation method has been developed rapidly. Andersen and Bollerslev [33], Barndorff-Nielsen and Shephard [34, 35], and Meddahi [36] have presented the use of the so-called realized variance measures by utilizing the information in the intraday data for measuring and forecasting volatilities. Barndorff-Nielsen and Shephard [37, 38] developed a series of the seminal work on bipower variation measure, which is then used to divide the $\mathrm{RV}$ into continuous diffusion volatility and jump volatility (see Andersen et al. [39] and Huang and Tauchen [40]). Under the reasonable presumption that jumps on financial markets are usually rare and large, we follow Huang and Tauchen [40] to assume that there is at most one jump per day and that the jump size dominates the daily return when a jump occurs. These assumptions allow us to extract the daily realized jumps and further to explicitly calculate the monthly jump intensity, size, and standard deviation. Tauchen and Zhou [29] have demonstrated that jump parameters can be precisely estimated and that the statistic inference is reliable.

Compared to parametric models, in which jump is estimated by the maximum likelihood, MCMC or GMM methods, nonparametric estimation has merit of convenient estimation without assuming specifying underlying drift, diffusion, and jump functions. The assumption of one jump per day fits to the compound Poisson jump process ([41] also utilizes the Poisson jump process to describe rare and large return jumps which are presumably the responses to the arrivals of important news), and it should be pointed out that bipower variation also works for the infinite activity jumps despite the fact that we focus only on the case of rare and large jumps. The following presents the details of jump estimation and detection.

Let $p_{t}=\log \left(P_{t}\right)$ denote the time $t$ logarithmic price of the asset, and assume that it evolves in continuous time as a jump-diffusion process:

$$
d p_{t}=\mu_{t} d t+\sigma_{t} d W_{t}+J_{t} d q_{t}
$$

where $d q_{t}$ is a Poisson jump process with intensity $\lambda_{J}$ and $J_{t}$ is the corresponding log jump size distribution following normal $\left(\mu_{J}, \sigma_{J}\right)$. Consider

$$
\mathrm{RV}_{t}=\sum_{j=1}^{M} r_{t, j}^{2} \longrightarrow \int_{t-1}^{t} \sigma_{s}^{2} d s+\int_{t-1}^{t} J_{s}^{2} d q_{s},
$$

where $M$ is the total number of trades during time $t$ and $t+1$ and $j$ is the indication for each trade. In the realistic financial markets, the price volatility of financial asset is not continuous but contains jumps due to the influence aroused by information shock on market. Barndorff-Nielsen and Shephard $[37,38]$ proposed two general measures for the quadratic variation process-realized variance and realized bipower variation; this is presented in the following:

$$
\mathrm{BV}_{t} \equiv \frac{\pi}{2} \frac{M}{M-1} \sum_{j=2}^{M}\left|r_{t, j}\right|\left|r_{t, j-1}\right| \longrightarrow \int_{t-1}^{t} \sigma_{s}^{2} d s,
$$

where $\sqrt{\pi / 2}=\mathrm{E}\left(\Pi_{t}\right), \Pi_{t}$ is a standardized normal distribution random variable, and $M /(M-1)$ is the amendment to 
sample size. According to Barndorff-Nielsen and Shephard, the difference between $\mathrm{RV}_{t}$ and $\mathrm{BV}_{t}$ is just the consistent estimator of the discrete jump variation when $M \rightarrow \infty$; that is,

$$
\mathrm{RV}_{t}-\mathrm{BV}_{t} \stackrel{M \rightarrow \infty}{\longrightarrow} \mathrm{RJV}_{t}
$$

A variety of jump detection techniques are proposed and studied by Barndorff-Nielsen and Shephard [37], Huang and Tauchen [40], and Andersen et al. [14]. In fact, in the process of calculating the discrete jump variation, the existence of different intraday sampling frequency may lead to some kind of calculation errors. Here, we adopt the ratio statistic favored by their findings:

$$
Z_{t}=\frac{\left(\mathrm{RV}_{t}-\mathrm{BV}_{t}\right) / \mathrm{RV}_{t}}{\sqrt{\left(\pi^{2} / 4+\pi-5\right)(1 / M) \max \left(1, \mathrm{TP}_{t} / \mathrm{BV}_{t}^{2}\right)}}
$$

where $\mathrm{TP}_{t}$ is the tripower quarticity that Barndorff-Nielsen and Shephard [37] define as

$$
\begin{aligned}
\mathrm{TP}_{t}= & \frac{M}{M-2} \cdot \frac{M}{4[\Gamma(7 / 6) / \Gamma(1 / 2)]^{3}} \\
& \cdot \sum_{i=3}^{M}\left|r_{t, i}\right|^{4 / 3}\left|r_{t, i-1}\right|^{4 / 3}\left|r_{t, i-2}\right|^{4 / 3} .
\end{aligned}
$$

The test statistic has an asymptotical normal distribution. Under the significance level, $1-\alpha$, we can get the estimate of the discrete jump variation:

$$
\mathrm{RJV}_{t}=I\left(Z_{t}>\Phi_{\alpha}^{-1}\right) \sqrt{\left[\mathrm{RV}_{t}-\mathrm{BV}_{t}\right]},
$$

where $\Phi$ is the cumulative distribution function of a standard normal and $I\left(Z_{t}>\Phi_{\alpha}^{-1}\right)$ is the resulting indicator function on whether there is a jump during the day; $I\left(Z_{t}>\Phi_{\alpha}^{-1}\right)$ equals 1 when a jump is detected at day $t$ and 0 otherwise. In the process of actual operation, we need to choose an appropriate $\alpha$, and Tauchen and Zhou [29] propose that when jump contributions are $10 \%$ and $80 \%$, the significance level should be 0.99 and 0.999 , respectively.

With the above test of $Z_{t}$ statistic and the related bipower variation theory, we can get the estimator of $\mathrm{RJV}_{t}$ and then calculate the monthly jump size (Size_RJV $\left.\mathrm{V}_{\text {month }}\right)$, monthly jump size mean (Mean_RJV $\mathrm{month}_{\text {mon }}$ ), monthy jump arrival rate (Arr_RJV $\left.V_{\text {month }}\right)$, and monthly jump size standard deviation $\left(\right.$ Std_RJV $\left.V_{\text {month }}\right)$. The jump components are defined as follows:

$$
\begin{aligned}
& \text { Size } \_ \text {RJV } V_{\text {month }}=\sum \text { Size_RJV } V_{\text {day }} \text {, } \\
& \text { Mean_RJV } V_{\text {month }}=\frac{\text { Size } \_R J V_{\text {month }}}{\text { N_RJV_days }} \text {, } \\
& \text { Arr } \_R J V_{\text {month }}=\frac{N \_ \text {RJV_days }}{\text { days }} \text {, } \\
& \text { Std } \_R J V \text { month }=\left[\sum\left(\left(\text { Size } \_R J V_{\text {day }}-M e a n \_R J V_{\text {day }}\right)^{2}\right)\right]^{1 / 2} \text {, }
\end{aligned}
$$

where $N \_$RJV_days is the total number of days when realized jump occurs and "days" denotes the trading days in a month. We follow the previous studies of China stock market to set the confidence level $\alpha$ at 0.95 in this paper. Our results show that, among 5 different capital-size portfolios, monthly jump size for the largest-cap portfolio is $8 \%$, and it is $9 \%$ for the smallest-cap portfolio. The jump size mean is significantly larger than 0 for all portfolios. Standard deviation is about $0.32 \sim 0.36 \%$, and jump arrival rate is about $19 \%$ for all portfolios.

\subsection{Jump Components Risk Factor Model under the Incomplete} Market. There are a few methods for measuring time-varying tail risk. First, Kelly and Jiang [20] devise a panel approach to estimate economy-wide conditional tail risk by using common fluctuation of the stocks. The framework is based on the long-run risk literature by Bansal and Yaron [21] and time-varying rare disaster model by Gabaix [24] as well as by Wachter [25]. Secondly, Bollerslev et al. [26] examine how the variance risk premium (VRP) implied in index option prices relates to the equity premium. As VRP is an ex-ante measure that represents investors' expectation for future risk, the realized jump is ex-post measure for tail risk.

Owing to the trading constraints, including shortselling constraint, liquidity issue, and budget constraint, the investors are not able to form market portfolio effectively and cannot diversify the nonsystematic risk away. As a result, the risk of the individual stock may need to be priced, and the risk information could be contained in the historical return characteristics (e.g., skewness and kurtosis.). This paper considers the jump the resource of stock risk and should affect the asset prices. We thus do an extensive investigation on the relation between jump risk and equity returns. Our empirical works cover the index returns, return of portfolios, and stock returns.

Guo and Robert [8] argue that it is the omitted variables problem that results in the failure of the CAPM, and they derive the equation about the effect of the idiosyncratic volatility on risk premium. Their argument is analogous to our reasoning on the tail risk of individual stock and can be expressed in following expression:

$$
\begin{aligned}
E_{t}\left(r_{i, t+1}\right)= & \gamma_{M} \operatorname{Cov}_{t}\left(r_{i, t+1}, r_{M, t+1}\right)+\gamma_{H} \operatorname{Cov}_{t}\left(r_{i, t+1}, r_{H, t+1}\right) \\
= & \gamma_{M} \frac{\operatorname{Cov}_{t}\left(r_{i, t+1}, r_{M, t+1}\right)}{\operatorname{Var}_{t}\left(r_{M, t+1}\right)} \operatorname{Var}_{t}\left(r_{M, t+1}\right) \\
& +\gamma_{H} \frac{\operatorname{Cov}_{t}\left(r_{i, t+1}, r_{H, t+1}\right)}{\operatorname{Var}_{t}\left(r_{H, t+1}\right)} \operatorname{Var}_{t}\left(r_{H, t+1}\right) \\
= & \gamma_{M} \beta_{i, M, t} \operatorname{Var}_{t}\left(r_{M, t+1}\right)+\gamma_{H} \beta_{i, H, t} \operatorname{Var}_{t}\left(r_{H, t+1}\right) .
\end{aligned}
$$

It says that the expected return on any asset is a function of conditional variances of stock market returns, $r_{M, t+1}$, and the risk factor, $r_{H, t+1}$, is omitted in the CAPM.

Under some moderate conditions, average idiosyncratic volatility $\left(\mathrm{IV}_{t}\right)$ is the proxy for volatility of $r_{H, t+1}$, and $\mathrm{MV}_{t}$ is 
the proxy of aggregate market volatility at time $t+1$; therefore, we can write

$$
r_{i, t+1}=\alpha_{i, t}+\gamma_{M} \beta_{i, M} \mathrm{MV}_{t}+\gamma_{H} \beta_{i, H} \mathrm{IV}_{t}+\zeta_{i, t+1} .
$$

For simplicity, we assume constant betas in (13), as Bollerslev et al. [27] do. Suppose that the intercept is zero; in (13), the loading on stock market volatility is equal to the market beta scaled by the price of market risk, $\gamma_{M}$. Similarly, the loading on idiosyncratic volatility is equal to the beta on the omitted risk factor scaled by its risk price, $\gamma_{H}$. Therefore, we can use (13) to explain the cross-sectional stock returns, even though we do not observe the risk factor, $r_{H, t+1}$. This method provides a direct link between time series and cross-sectional stock return predictability. If the value premium is an omitted risk factor, as argued by Fama and French [28], we can expect that its volatility should have predictive power for the stock returns similar to that of average idiosyncratic volatility.

Jump volatility risk shares similar characteristics regarding what generates IV. For example, Bollerslev et al. [27] provide a new framework for estimating the systematic and idiosyncratic jump tail risks in financial asset pricing. In their paper, the opinion dispersion is subsequently related to the jump, and it should be pointed out that their concept is also relevant to incomplete market hypothesis. Therefore, the theoretical argument over idiosyncratic volatility and jump volatility risk on equity returns is based on incomplete market foundation.

For an individual stock, the jump could result from nonsystematic information as well as systematic information. According to the theory, the index jump carries the systematic information, which also leads to the jump of individual stocks. Therefore, when investigating the nonsystematic jump effect on the returns, we also do both regressions with market jumps as well as without market jumps separately. In Section 4, we examine the nonsystematic and systematic jump effects on the returns of index, portfolios, and stocks. Our regression models for the stock return and portfolio are the following:

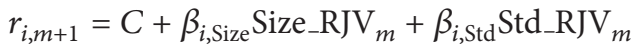

$$
\begin{aligned}
& +\beta_{i, \text { Arr }} \text { Arr_RJV }_{t}+\zeta_{M, m+1} \text {, }
\end{aligned}
$$

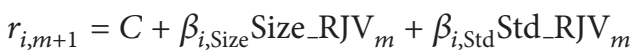

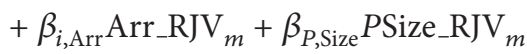

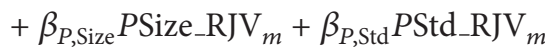

$$
\begin{aligned}
& +\zeta_{M, t+1} \text {. }
\end{aligned}
$$

As for index return, the estimation model is given as follows:

$$
\begin{aligned}
& r_{P, m+1}= \alpha_{P}+\beta_{P, \text { size }} P \text { Size } \_ \text {RJV } \\
& m \\
& \\
&+\beta_{P, \text { Arr }} P \text { Arr_RJV } \\
& m \\
&+\zeta_{P, m+1} .
\end{aligned}
$$

For each individual stock, Size_RJV, Std_RJV, and Arr_RJV denote monthly jump size, jump standard deviation, and jump arrival rate, respectively. PSize_RJV, PStd_RJV, and PArr_RJV represent monthly market index jump size, index jump standard deviation, and index jump arrival rate. $m$ is the indication of month. $i$ and $p$ are notations for individual stock (portfolio) and index (market portfolio). In the robustness tests, we run the regression models incorporating FamaFrench factors and regression models with nonlinear jump components. Those models are given as follows:

$$
\begin{aligned}
& r_{i, m+1}= C+\beta_{i, \text { Size }} \text { Size_RJV }_{m}+\beta_{i, \text { Std }} \text { Std_RJV }_{m} \\
&+\beta_{i, \text { Arr }} \text { Arr_RJV } \\
&+\gamma_{i, \text { size }} \text { Size }_{-} \mathrm{RJV}_{m} * \text { Arr_RJV } \\
&+\gamma_{i, \text { std }} \text { Std_RJV } \\
& m
\end{aligned}
$$

$$
\begin{aligned}
& r_{i, m+1}=C+\beta_{i, \text { Size }} \text { Size } \_ \text {RJV } m
\end{aligned}
$$

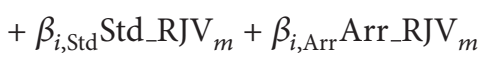

$$
\begin{aligned}
& +\gamma_{i, \text { size_Arr }} \text { Size_RJV } m * \text { Arr_RJV }{ }_{m} \\
& +\gamma_{i, \text { std_Arr }} \text { Std_RJV }_{m} * \text { Arr_RJV }_{m} \\
& +\beta_{P, \text { Size }} P \text { Size_RJV }{ }_{m}+\text { PStd_RJV } m
\end{aligned}
$$

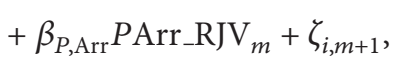

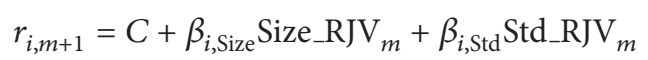

$$
\begin{aligned}
& +\beta_{i, \text { Arr }} \text { Arr_RJV } m+\beta_{P, \text { Size }} P \text { Size_RJV } m \\
& +\beta_{P, \text { Std }} P S t d \_R J V_{m}+\beta_{P, \text { Arr }} P \text { Arr_RJV } m \\
& +\gamma_{\mathrm{SMB}} \mathrm{SMB}_{m}+\gamma_{\mathrm{HML}} \mathrm{HML}_{m}+\zeta_{i, m+1} .
\end{aligned}
$$

When (17) expands (14) to include the nonlinear jump multiple terms, Size_RJV ${ }_{m} *$ Arr_RJV ${ }_{m}$, Std_RJV $m *$ Arr_RJV ${ }_{m}$, into repressors, (18) extends (17), so we can test nonlinearity effect of jump components under the control of the index jump components. Finally, (19) is used to investigate the nonlinear jump effect on return with control of Fama-French factors.

\section{Estimation of Jump Components}

3.1. Data and Summary Statistics. Intraday high-frequency trading contains noises. On the one hand, low sampling frequency may fail to depict the actual volatility information on that day. On the other hand, high sampling frequency may lead to the problem of micronoise which may affect the results. As suggested by the former literature, we use five-minute high-frequency data for return calculation. To minimize the noise, we then divide 200 randomly selected stocks into 5 portfolios based on the stock market value and then use the equally weighted return for realized jump estimation. The data comes from the CSMAR high-frequency database, and sampling period begins from January 4, 2007, and ends on October 31, 2013. There are 82 months and 49 transactions per day (including one overnight trading data and 48 intraday trading data). The individual stocks' monthly returns and the index returns are directly from the CSMAR financial database. We calculate all monthly jump components from high-frequency transaction and run the 

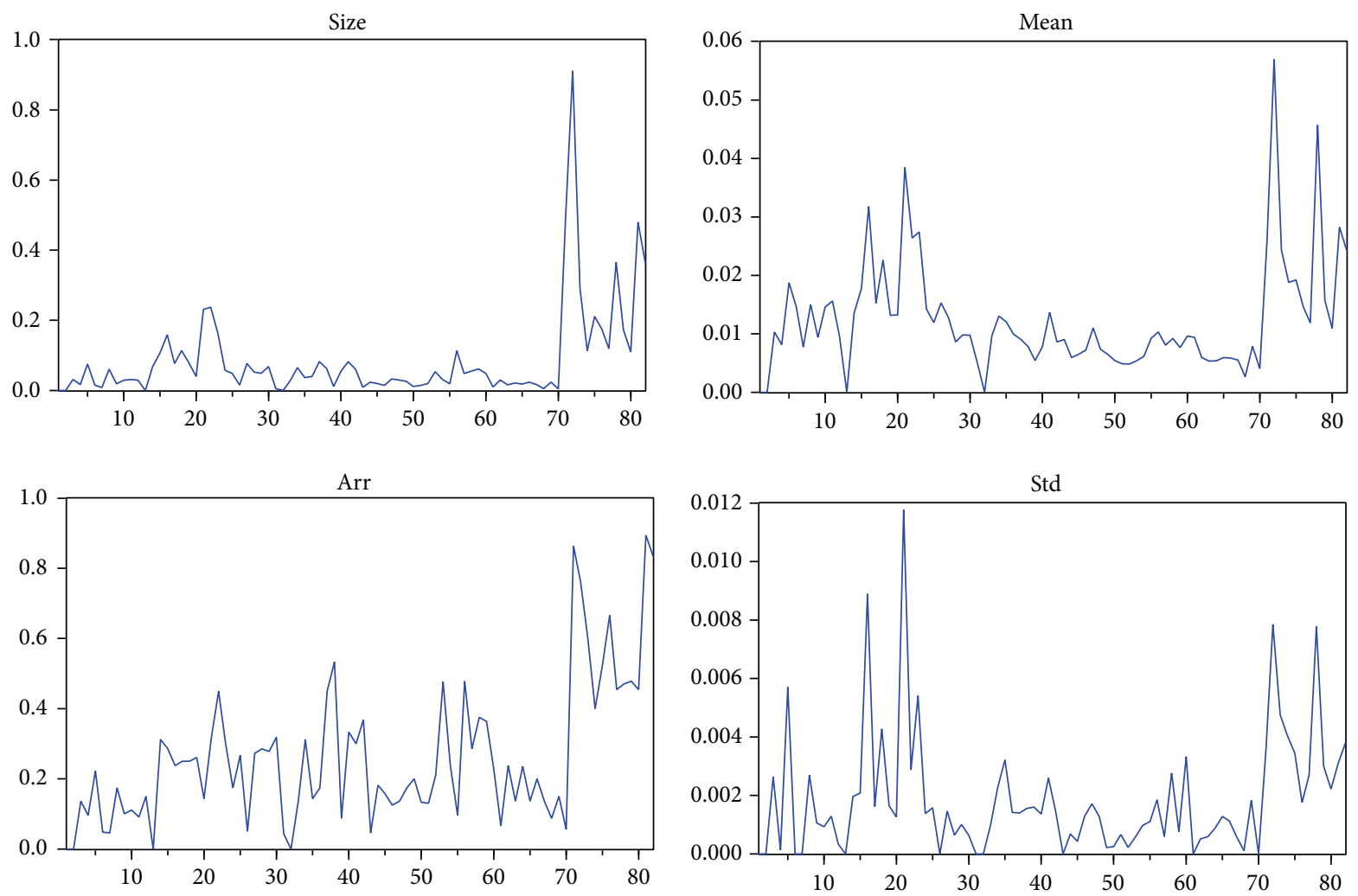

Figure 1: Time series characteristic of index jump components.

TABLE 1: Descriptive statistics for index jump components.

\begin{tabular}{lcccc}
\hline Index 000002 & Size & Mean & Arr & Std \\
\hline Mean & 0.0864 & 0.0124 & 0.2608 & 0.0019 \\
Median & 0.0437 & 0.0096 & 0.2247 & 0.0013 \\
Maximum & 0.9120 & 0.0570 & 0.8947 & 0.0118 \\
Minimum & 0.0000 & 0.0000 & 0.0000 & 0.0000 \\
Std. dev. & 0.1361 & 0.0096 & 0.1990 & 0.0021 \\
Skewness & 3.6540 & 2.1444 & 1.2761 & 2.2811 \\
Kurtosis & 19.4318 & 9.0465 & 4.5444 & 9.2647 \\
Jarque-Bera & 1104.99 & 187.76 & 30.40 & 205.21 \\
Probability & 0.0000 & 0.0000 & 0.0000 & 0.0000 \\
\hline
\end{tabular}

regression on monthly return over monthly jump components.

For market-level (systematic) realized jump estimation, our sample data is high-frequency return of Shanghai composite index. Table 1 demonstrates descriptive statistics of index jump components, and Figure 1 shows the time series of index jump components.

In comparison with the study of Tauchen and Zhou [29] on S\&P, the A-share index jump size mean is $1.24 \%$, while it is $6.5 \%$ for S\&P index. The jump arrival rates are $26.08 \%$ for Shanghai index and $13.3 \%$ for S\&P index; standard deviations are $0.19 \%$ for Shanghai index and $0.525 \%$ for $\mathrm{S} \& \mathrm{P}$ index. The difference is mainly due to the different significant level selected for jump filtration. Our paper sets $\alpha$ equal 0.95 , allowing smaller jumps and increasing the jump arrival rate. Therefore, we have a larger sample size of realized jumps, and larger sample size leads to lower jump size variance. Additionally, as self-evident in Figure 1, the jump components are apparently time varying.

Table 2 shows the jump statistics of the largest-cap and second largest-cap portfolios, each of which contains 40 stocks. And Figure 2 demonstrates time series of jump components for size 1 portfolio.

Compared with jump components of index return, the magnitude of monthly jump size mean is larger for portfolios, and the arrival rate tends to be lower. The way we sort the portfolios by the size of capitalization is inspired not only by traditional cross-sectional return researches but also by Bollerslev et al. works in $[27,30]$, in which they show that their model works better for large cap stocks or for stocks traded actively (descriptive statistics for other portfolios are listed in the appendix). While the statistics of portfolio with smaller size stocks are shown in the appendix, we find very interesting pattern over jump components of 5 portfolios. As seen in Table 3 and Figure 3, monthly jump size, jump mean, jump intensity, and jump size variance tend to be lower for larger capitalization stocks. Therefore, jump components may capture the similar information of the size factor.

3.2. Jump Components of the Index and of the Individual Stock. In Figure 4, we compare jump components of individual stock, the largest-cap portfolio, and index over our sample 

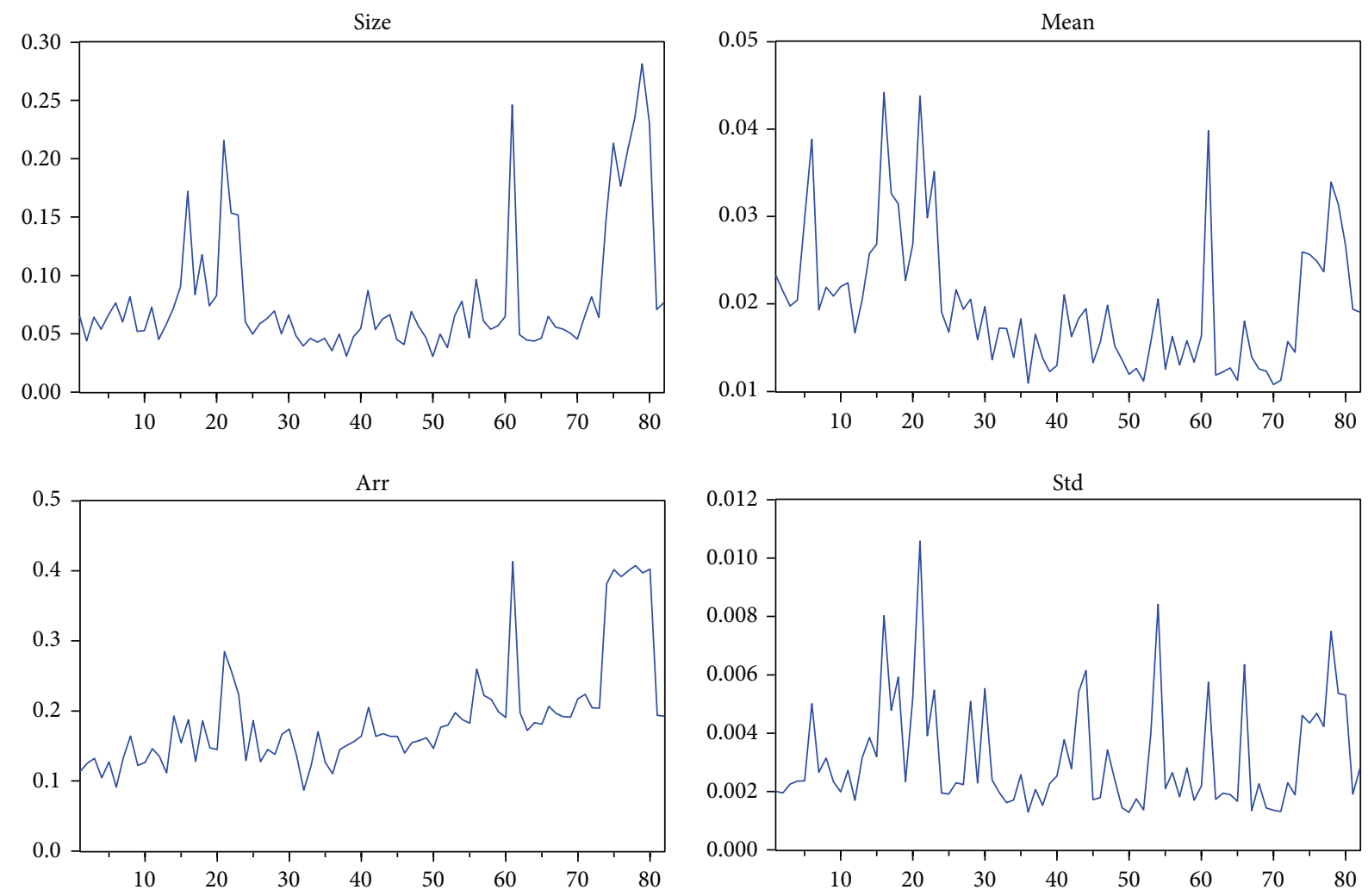

FIGURE 2: Time series characteristic of individual-based portfolio.
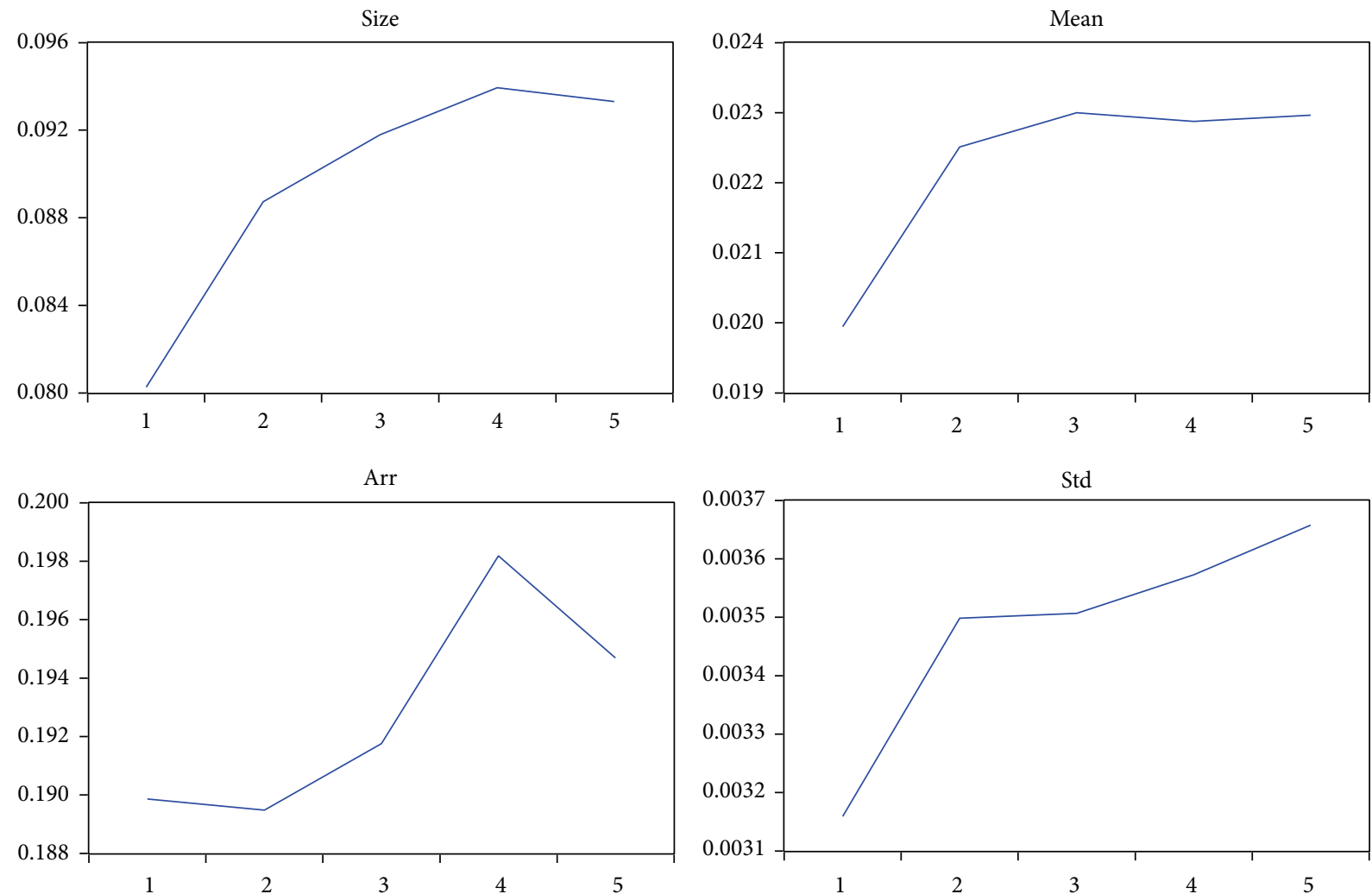

FIGURE 3: Trend of jump components for portfolios. 
TABle 2: Descriptive statistics of jump components for size 1 and size 2 portfolios.

\begin{tabular}{lccccccccc}
\hline SZ1 & Size & Mean & Arr & Std & SZ2 & Size & Mean & Arr & Std \\
\hline Mean & 0.0803 & 0.0199 & 0.1899 & 0.0032 & Mean & 0.0887 & 0.0225 & 0.1895 & 0.0035 \\
Median & 0.0617 & 0.0187 & 0.1713 & 0.0023 & Median & 0.0656 & 0.0202 & 0.1707 & 0.0029 \\
Maximum & 0.2813 & 0.0442 & 0.4134 & 0.0106 & Maximum & 0.3011 & 0.0488 & 0.4264 & 0.0097 \\
Minimum & 0.0304 & 0.0108 & 0.0870 & 0.0013 & Minimum & 0.0429 & 0.0119 & 0.1065 & 0.0014 \\
Std. dev. & 0.0553 & 0.0077 & 0.0786 & 0.0019 & Std. Dev. & 0.0596 & 0.0082 & 0.0744 & 0.0018 \\
Skewness & 2.0477 & 1.2664 & 1.7262 & 1.5554 & Skewness & 2.0234 & 1.1964 & 1.9767 & 1.3557 \\
Kurtosis & 6.2403 & 4.3168 & 5.3520 & 5.3717 & Kurtosis & 6.0927 & 4.1452 & 6.1131 & 4.5256 \\
Jarque-Bera & 93.181 & 27.843 & 59.623 & 52.283 & Jarque-Bera & 88.634 & 24.043 & 86.513 & 33.071 \\
Probability & 0.0000 & 0.0000 & 0.0000 & 0.0000 & Probability & 0.0000 & 0.0000 & 0.0000 & 0.0000 \\
\hline
\end{tabular}

TABLE 3: Descriptive statistics of jump components for portfolios.

\begin{tabular}{lcccc}
\hline Portfolio mean & Size & Mean & Arr & Std \\
\hline SZ1 & 0.0803 & 0.0199 & 0.1899 & 0.0032 \\
SZ2 & 0.0887 & 0.0225 & 0.1895 & 0.1918 \\
SZ3 & 0.0918 & 0.0230 & 0.1982 & 0.0035 \\
SZ4 & 0.0939 & 0.0229 & 0.1947 & 0.0036 \\
SZ5 & 0.0933 & 0.0230 & 82 & 0.0037 \\
\hline Observations & 82 & 82 & 82 \\
\hline
\end{tabular}

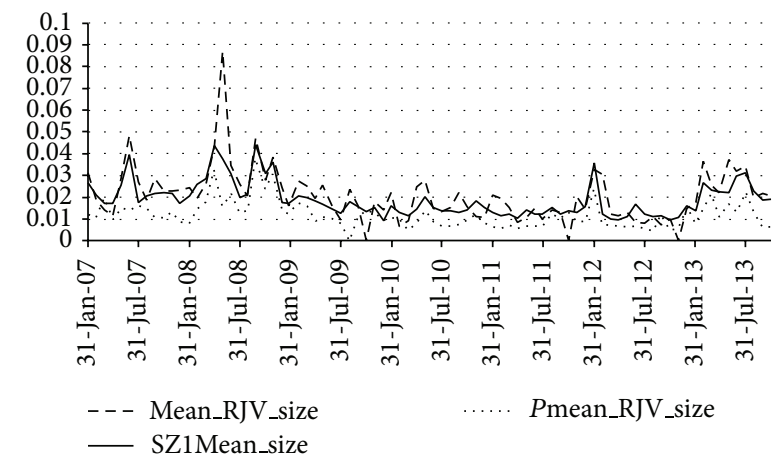

FIGURE 4: Jump size mean for a stock, a size 1 portfolio, and an Ashare index.

period. The stock is one randomly picked stock in size 1 portfolio, and we can find the jump comovements between the stock, portfolio, and index. In this quick glance, the monthly jump size mean is the largest for the individual stock and the lowest for the index. The figure strongly implies that index jump components could also be a proxy for the systematic risk.

\section{Forecasting One-Month-Ahead Equity Returns}

Realize that jump components have been applied for predicting and explaining the return of market in the USA and China. However, for the return of stock and portfolio, no empirical work has been done by using the realized jump measure. The existing researches for stock market in China mainly have been focusing on either macroeconomic
TABLE 4: Forecasting one-month-ahead index returns using realized jump risk factor model.

\begin{tabular}{lccccc}
\hline Variables & $C$ & PSize & PArr & PStd & Adj. $R^{2}$ \\
\hline Coefficients & 0.027 & $0.278^{* *}$ & -0.055 & $-18.695^{* * *}$ & 0.080
\end{tabular}

Note: The numbers in the table are coefficients, and “*”, “**”, “***” represents $10 \%, 5 \%$ and $1 \%$ significance level, same for the following tables.

TABLE 5: Forecasting one-month-ahead individual stock returns using realized jump volatility-based factor model.

\begin{tabular}{lccccc}
\hline Stock & $C$ & Size_RJV & Arr_RJV & Std_RJV & Adj. ${ }^{2}$ \\
\hline 600362 & $0.115^{* * *}$ & $0.977^{*}$ & $-0.760^{* *}$ & -9.494 & 0.047 \\
600100 & 0.044 & 0.533 & -0.357 & $-3.494^{*}$ & 0.010 \\
600859 & 0.037 & $0.602^{*}$ & -0.206 & $-14.241^{* *}$ & 0.039 \\
\hline
\end{tabular}

variables or Fama-French multifactor models. Our paper thus makes the contribution of applying jump components to study the equity return and exploring their power to predict the return. By aggregating the daily realized jump into monthly jump size, we then use the monthly realized jump components as risk factors to explain one-monthahead equity return. Meanwhile, we also consider index jump components systematic risks and add them as control variables in our tests.

4.1. Forecasting One-Month-Ahead Index Return. For the market-level realized jump, our sample is the return of Shanghai composite A-share index (000002). Because the calculations of monthly jump size and monthly jump size mean are highly related, we use monthly jump size as one of the explanatory variables. Table 4 shows the results of regression. In linear model, the monthly jump size (Psize) 
TABLE 6: Forecasting one-month-ahead individual stock portfolio returns using realized jump volatility-based factor model with market-level jump components.

\begin{tabular}{|c|c|c|c|c|c|c|c|c|}
\hline Stock & $C$ & Size_RJV & Arr_RJV & Std_RJV & Psize & PStd & PArr & $\operatorname{Adj} . R^{2}$ \\
\hline 600362 & -0.04 & $6.024^{* *}$ & -0.02 & $-12.957^{* *}$ & 5.045 & -0.042 & $-33.608^{* *}$ & 0.113 \\
\hline 600100 & $0.072^{* *}$ & $0.654^{*}$ & -0.39 & $-3.818^{*}$ & 0.305 & -0.108 & -15.798 & 0.015 \\
\hline 600859 & $0.057^{*}$ & $0.890^{* *}$ & -0.251 & $-15.176^{* * *}$ & 0.135 & -0.014 & $-22.315^{* * *}$ & 0.104 \\
\hline
\end{tabular}

TABLE 7: Forecasting one-month-ahead individual-based portfolio returns using realized jump volatility-based factor model.

\begin{tabular}{lcccc}
\hline Size & $C$ & Size_RJV & Std_RJV & Arr_RJV \\
\hline 1 & $0.073^{* *}$ & 0.725 & $-13.634^{*}$ & -0.379 \\
2 & $0.120^{* *}$ & $1.390^{* *}$ & -20.060 & $-0.823^{* *}$ \\
3 & $0.107^{* *}$ & $1.132^{*}$ & $-26.017^{*}$ & -0.539 \\
4 & 0.099 & 1.117 & -19.607 & $-0.588^{*}$ \\
5 & 0.079 & 0.848 & -11.404 & -0.517 \\
\hline
\end{tabular}

and monthly jump standard deviation (Pstd) are significant, while the coefficients are positive for the jump size and negative for jump standard deviation. It is quite intuitive that the larger jump size implies higher tail risk such that investors require higher return. However, the negative sign for jump standard deviation is not easy to comprehend.

While Guo and Robert $[7,8]$ also find that the average idiosyncratic volatility has negative coefficients on future index return, they claim that the average idiosyncratic volatility may capture the information of opportunity cost. When higher opportunity lowers the return, the increase of idiosyncratic volatility decreases the returns. We thus conjecture that the jump standard deviation may also catch the information of opportunity cost.

4.2. Forecasting One-Month-Ahead Stock Return. Following Bollerslev et al. [27, 30], using top 40 large cap stocks or stocks traded actively for empirical analysis, we also pick up large cap stocks among our randomly selected stocks for predicting power tests. For each stock, we first regress the individual stock's return on its realized jump components and then add market components into explanatory variables for advanced investigation. Tables 5 and 6 demonstrate the results of two regressions for 3 large cap stocks. The results of more stocks listed in our largest-cap portfolio are shown in the appendix. According to the results for stock, we find that jump size is commonly a tail risk factor in explaining the future return, and at least one jump component is a significant factor in regression.

Moreover, the coefficient signs for jump size and jump standard deviation are consistent with the results of index return. From the general equilibrium perspective, if the tail risk cannot be diversified away, higher jump size implies higher tail risk and requires higher return for compensation. As for negative relation between return and jump standard deviation, we think that the jump standard deviation is highly negatively correlated with book-to-market ratio for the success or failure of a project, leading to the jump, has stronger impact on stocks with lower book-to-market ratio. Hence, higher jump size deviation implies lower book-tomarket ratio. While Gou and Robert $[7,8]$ empirically show the negative correlation between idiosyncratic volatility and book-to-market ratio, we are collecting more accounting information for another further work. Table 6 shows the results with the control of market jump components. The Adj. $R^{2}$ increases after we include index jump components into the regression model.

4.3. Forecasting One-Month-Ahead Portfolio Return. For portfolio return analysis, we apply the convention of crosssection return research which divides the total sample into 5 portfolios based on the stock market capital size. Using the portfolio return helps us to reduce the trading noise of the individual stock. As a few researches apply realized jump to study the index return, we supplement the first empirical study of realized jump effect on the portfolio and the stock return. Similar to our empirical work on stocks, we first estimate portfolio return over the portfolio jump components and show the results in Table 7. Then, we include the market index jump components as the control variables and list the results in Table 8.

According to Table 7, the jump components work better to explain the future return for larger-cap portfolios, including size 1 to size 3 . For smaller size portfolios (size 4 and size 5), the jump components perform marginally in predicting return. The Adj. $R^{2}$ is also very low for small cap portfolio. Those results are consistent with the paper by Bollerslev et al. $[27,30]$, in which they show that their model performs better for large cap stocks. In addition, the signs of the coefficients agree with results of index and stocks. Our conclusion does not alter if we add market-level jump components into the regression model; however, the explaining power of the model increases greatly. With the control of market jump components, all of jump components, including monthly jump size (Size_RJV), jump standard deviation (Std_RJV), and arrival rate (Arr_RJV), become significant for size 2 portfolios. Finally, we find that jump arrival rate also has significantly negative impact on return for large cap portfolio. However, the role of jump arrival rate should not be overemphasized, because size has correlations with jump arrival rate owing to jump detection statistics design. In this paper, we set $\alpha$ equal to 0.95 , leading to jump size mean ranging from 
TABLE 8: Forecasting one-month-ahead individual-based portfolio returns using realized jump volatility-based factor model with marketlevel jump components.

\begin{tabular}{lcccccccc}
\hline Size & $C$ & Size_RJV & Arr_RJV & Std_RJV & Psize & $P$ Arr & PStd & 0.033 \\
\hline 1 & $0.083^{* *}$ & $1.237^{*}$ & $-0.581^{*}$ & -9.260 & -0.170 & 0.033 & 0.047 \\
2 & $0.139^{* *}$ & $2.022^{* *}$ & $-1.092^{* *}$ & $-16.304^{* *}$ & -0.171 & $0.042^{* *}$ & $0.042^{* *}$ & 0.108 \\
3 & $0.099^{*}$ & 1.184 & -0.597 & -12.683 & 0.246 & $-0.036^{*}$ & $-0.036^{*}$ & 0.040 \\
4 & 0.088 & $1.649^{*}$ & -0.728 & -7.980 & -0.272 & -0.009 & -0.009 & 0.057 \\
5 & 0.088 & 1.389 & -0.620 & -7.020 & 0.112 & -0.086 & -0.086 & 0.015 \\
\hline
\end{tabular}

TABLE 9: Forecasting one-month-ahead individual returns using realized jump volatility-based factor model with FF factors.

\begin{tabular}{ccccccccccc}
\hline & $C$ & Size_RJV & Arr_RJV & Std_RJV & Psize & PArr & $P S t d$ & SMB & HML & Adj. $R^{2}$ \\
\hline 600362 & $0.150^{* * *}$ & $1.280^{* *}$ & $-0.806^{* *}$ & -11.864 & $0.484^{*}$ & -0.089 & $-35.944^{* * *}$ & -0.049 & -0.671 & 0.103 \\
600100 & $0.067^{*}$ & $0.643^{*}$ & -0.382 & $-3.764^{*}$ & 0.300 & -0.110 & -14.427 & 0.258 & 0.027 & 0.015 \\
600859 & 0.047 & $0.882^{*}$ & -0.260 & $-15.119^{* *}$ & 0.118 & -0.011 & $-19.235^{* *}$ & $0.597^{*}$ & 0.133 & 0.123 \\
\hline
\end{tabular}

TABLE 10: Forecasting one-month-ahead individual returns using realized jump volatility-based factor model with cross-term.

\begin{tabular}{ccccccccccc}
\hline & $C$ & Size_RJV & Arr_RJV & Std_RJV & Psize & PArr & PStd & Std * Arr & Size * Arr & Adj. $R^{2}$ \\
\hline 600362 & $0.167^{* * *}$ & $1.842^{* *}$ & $-0.837^{* *}$ & $-40.387^{*}$ & $0.513^{*}$ & -0.112 & $-40.058^{* *}$ & 129.012 & -2.333 & 0.115 \\
600100 & $0.087^{* *}$ & -0.185 & -0.31 & 3.484 & 0.256 & -0.113 & -8.573 & -51.175 & 2.044 & 0.018 \\
600859 & 0.047 & 0.761 & -0.249 & -2.221 & 0.138 & -0.009 & $-22.127^{* * *}$ & -69.190 & 1.124 & 0.096 \\
\hline
\end{tabular}

TABLE 11: Forecasting one-month-ahead index returns using realized jump volatility-based factor model with cross-term of its jump components.

\begin{tabular}{cccccccr}
\hline Index & $C$ & $P$ size & $P$ Arr & $P$ Std & Std $*$ Arr & Size $*$ Arr & Adj. $R^{2}$ \\
\hline & 0.015 & 0.691 & -0.042 & -8.972 & -56.573 & 0.162 \\
\hline 000002 & $C$ & $P$ size & $P$ Arr & $P$ Std & & Adj. $R^{2}$ \\
\hline & 0.027 & $0.278^{* *}$ & -0.055 & $-18.695^{* * *}$ & & 0.080 \\
\hline
\end{tabular}

1 to $3 \%$ and jump arrival rate ranging from 15 to $25 \%$. If the confidence level $\alpha$ increases to 0.99 , the stricter criteria naturally discriminate against smaller jumps. As a result, out data contains only larger jumps, leading to lower arrival rate. This paper follows the previous study, using the ease criteria to filter the jump. Compared with Tauchen and Zhou [29], documenting $6 \%$ jump size mean, our jump size mean is $2 \%$ and is more practical for nature of jump dynamics.

In summary of $4.1,4.2$, and 4.3 , the monthly jump size (Size_RJV) is a significant risk factor which positively influences one-month-ahead return, while the jump size standard deviation (Std_RJV) has negative impact on the return. After including market jump components, we derive the same conclusion and find the increased Adj. $R^{2}$. Overall, as shown in the appendix, even for the individual stock, at least one jump component is a significant factor for return with or without the control of market jump components.

\section{Robustness Tests}

In this section, we proceed with the robustness tests from two perspectives. First, because many empirical works use Fama-French factor models to explain cross-sectional returns, this paper thus compares jump risk factors together with size and book-to-market ratio for stock return. Secondly, we consider jump components' nonlinear effect on return; therefore, the multiples of jump risk factors are added to regression models for advanced tests. If those multiple terms are significant and greatly improve the predicting power, then the effect of jump risk factors on return is probably nonlinear.

Table 9 shows the jump risk factors regression with control of size (SMB) and book-to-market ratio (HML) for stocks. The jump size and standard deviation remain significant, and Adj. $R^{2}$ does not increase. Additionally, FamaFrench factors are not significant. In other words, the onemonth-ahead return is influenced by the jump effect rather than FF factors.

Table 10 demonstrates the results of regressions which incorporate the multiples of jump risk factors. Though Adj. $R^{2}$ improves slightly, the multiple terms are not significant.

Table 11 shows the robustness results for index jump effect on the returns. As seen, not only nonlinear terms, Std * Arr and Size $*$ Arr, are insignificant, but also Adj. $R^{2}$ drops.

Table 12 shows the robustness results for 5 portfolios. After adding control variables of multiple terms, all jump components became insignificant for size 1 portfolio. While Adj. $R^{2}$ does not increase, the nonlinear terms are not significant. 
TABLE 12: Forecasting one-month-ahead individual-based portfolio returns using realized jump volatility-based factor model with cross-term of its jump components.

\begin{tabular}{lcccccccccc}
\hline Size & $C$ & Size_RJV & Arr_RJV & Std_RJV & Psize & $P$ Arr & $P S t d$ & Std $*$ Arr & Size $*$ Arr & Adj. $R^{2}$ \\
\hline 1 & 0.091 & 1.139 & -0.612 & -10.041 & -0.146 & 0.028 & -15.147 & 5.862 & 0.194 & 0.020 \\
2 & 0.146 & $4.829^{*}$ & $-1.439^{*}$ & -74.502 & -0.734 & 0.156 & $-27.168^{* *}$ & 295.313 & -9.148 & 0.103 \\
3 & 0.058 & 2.062 & -0.491 & -18.227 & 0.070 & 0.000 & $-23.763^{*}$ & 8.667 & -2.071 & 0.017 \\
4 & 0.111 & 3.156 & -0.946 & -45.107 & -0.560 & 0.032 & $-23.857^{*}$ & 146.138 & -4.150 & 0.040 \\
5 & 0.099 & 2.762 & -0.756 & -40.191 & -0.021 & -0.054 & $-28.734^{* *}$ & 145.713 & -4.528 & 0.042 \\
\hline
\end{tabular}

Size 1 to size 5 portfolios are arranged in the order of capitalization. Size 1 is the largest-cap portfolio, while size 5 is the smallest-cap portfolio. The numbers in the table are coefficients, and “*”, “**”, and “***” represent $10 \%, 5 \%$, and $1 \%$ significance levels.

TABLE 13: Descriptive statistics of jump components for size 3 to size 5 portfolios.

\begin{tabular}{|c|c|c|c|c|c|c|c|c|c|c|c|c|c|c|}
\hline SZ3 & Size & Mean & Arr & Std & SZ4 & Size & Mean & Arr & Std & SZ5 & Size & Mean & Arr & Std \\
\hline Mean & 0.0918 & 0.0230 & 0.1918 & 0.0035 & Mean & 0.0939 & 0.0229 & 0.1982 & 0.0036 & Mean & 0.0933 & 0.0230 & 0.1947 & 0.0037 \\
\hline Median & 0.0690 & 0.0212 & 0.1756 & 0.0030 & Median & 0.0719 & 0.0200 & 0.1778 & 0.0030 & Median & 0.0712 & 0.0210 & 0.1727 & 0.0033 \\
\hline Maximum & 0.3286 & 0.0508 & 0.4283 & 0.0090 & Maximum & 0.3002 & 0.0505 & 0.4330 & 0.0089 & Maximum & 0.2663 & 0.0499 & 0.4324 & 0.0095 \\
\hline Minimum & 0.0326 & 0.0131 & 0.0855 & 0.0012 & Minimum & 0.0447 & 0.0140 & 0.1032 & 0.0018 & Minimum & 0.0386 & 0.0147 & 0.1085 & 0.0011 \\
\hline Std. dev. & 0.0604 & 0.0081 & 0.0779 & 0.0016 & Std. dev. & 0.0568 & 0.0079 & 0.0759 & 0.0016 & Std. dev. & 0.0552 & 0.0077 & 0.0762 & 0.0016 \\
\hline Skewness & 2.0464 & 1.3540 & 1.6768 & 1.3756 & Skewness & 1.9224 & 1.5546 & 1.7292 & 1.5800 & Skewness & 1.6370 & 1.5211 & 1.5507 & 1.4567 \\
\hline Kurtosis & 6.6092 & 4.6886 & 5.3955 & 4.5527 & Kurtosis & 5.8266 & 5.1466 & 5.4538 & 5.1632 & Kurtosis & 4.8022 & 5.0022 & 4.7581 & 5.1850 \\
\hline Jarque-Bera & 101.74 & 34.799 & 58.033 & 34.099 & Jarque-Bera & 77.807 & 48.773 & 61.438 & 50.105 & Jarque-Bera & 47.720 & 45.318 & 43.423 & 45.311 \\
\hline \multirow[t]{2}{*}{ Probability } & 0.0000 & 0.0000 & 0.0000 & 0.0000 & Probability & 0.0000 & 0.0000 & 0.0000 & 0.0000 & Probability & 0.0000 & 0.0000 & 0.0000 & 0.0000 \\
\hline & & & & & & & & & & Observations & 82 & 82 & 82 & 82 \\
\hline
\end{tabular}

TABLE 14: Descriptive statistics for individual stock average jump components.

\begin{tabular}{lcccc}
\hline 600362 & Size & Mean & Arr & Std \\
\hline Mean & 0.106062 & 0.023454 & 0.216076 & 0.003758 \\
Median & 0.074818 & 0.023504 & 0.195238 & 0.002885 \\
Maximum & 0.528641 & 0.063170 & 0.733333 & 0.018655 \\
Minimum & 0.000000 & 0.000000 & 0.000000 & 0.000000 \\
Std. dev. & 0.090047 & 0.011790 & 0.135851 & 0.003497 \\
Skewness & 1.740065 & 0.680288 & 0.938441 & 1.552614 \\
Kurtosis & 7.637096 & 3.866075 & 4.460514 & 6.301100 \\
Jarque-Bera & 114.8477 & 8.887622 & 19.32393 & 70.17733 \\
Probability & 0.000000 & 0.011751 & 0.000064 & 0.000000 \\
\hline
\end{tabular}

In short, after controlling size and value factors, we find that the realized jump risk can explain and predict the equity return. Therefore, jump is an important risk factor needed to be considered for asset pricing and risk management. We also find that nonlinear models do not work better than linear models [31].

\section{Conclusion}

For risk-aversion investors, jump risk, which leads to return distribution with fat tail, can greatly affect investors' perception about how risky a company is or how it captures the risk information. As long as nonsystematic risk of the individual stock cannot be diversified away, the firm-level and industrylevel risk should be priced into the return. This paper applies the realized jump, considers a measure of tail risk, and uses high-frequency data to estimate jump components including jump size mean, jump size standard deviation, and jump intensity. We argue that trading constraints make investors unable to diversify nonsystematic risk away; hence, the tail risk should be priced, and jump should be able to explain the asset return.

Our data contain high-frequency trades of 200 randomly selected stocks which are the composite stocks for Shanghai composite index. Our empirical works are divided into 3 parts, including index return, portfolio returns, and stock returns. Under the control of Fama-French factors, our results show that jump factors can explain one-month-ahead return for index, high cap portfolio, and high cap stocks. Moreover, we also try to use nonlinear combinations of jump components to explain and predict the returns. However, no evidence supports that the nonlinear models are better than linear models.

In our research, the monthly jump size and jump size standard deviation are generally significant factors for equity return. The positive coefficient for jump size is quite intuitive as it is directly linked to the tail risk. However, the negative coefficient for jump size standard deviation is for the first time documented in the literature. We claim that the jump standard deviation is positively related to opportunity cost which decreases the returns, as similar argument was made for the idiosyncratic volatility. Obviously, further theoretical models are needed after we find that jump components can explain the return. We are also looking forward to the theory model delivering the insights about how jump components are prices and looking forward to seeing more empirical 
TABLE 15

\begin{tabular}{|c|c|c|c|c|c|c|c|c|c|c|}
\hline & $C$ & Size_RJV & Arr_RJV & Std_RJV & & & & & & $\overline{\operatorname{Adj} . R^{2}}$ \\
\hline \multirow[t]{2}{*}{600066} & 0.039 & -0.162 & 0.069 & -4.371 & & & & & & 0.051 \\
\hline & C & Size_RJV & Arr_RJV & Std_RJV & $P$ size & PArr & PStd & & & $\overline{\text { Adj. } R^{2}}$ \\
\hline \multirow[t]{2}{*}{600066} & $0.056^{*}$ & 0.145 & -0.058 & $-5.543^{*}$ & 0.165 & 0.017 & $-17.954^{*}$ & & & 0.069 \\
\hline & $C$ & Size_RJV & Arr_RJV & Std_RJV & $P$ size & PArr & PStd & Std $*$ Arr & Size $*$ Arr & $\operatorname{Adj} . R^{2}$ \\
\hline \multirow[t]{2}{*}{600066} & 0.028 & 0.601 & -0.024 & 5.626 & 0.147 & 0.051 & $-19.204^{* *}$ & -68.284 & -0.303 & 0.062 \\
\hline & $C$ & Mean_RJV & Arr_RJV & Std_RJV & & & & & & $\operatorname{Adj} . R^{2}$ \\
\hline \multirow[t]{2}{*}{600276} & 0.003 & -1.517 & $0.138^{*}$ & $4.749^{*}$ & & & & & & 0.045 \\
\hline & $C$ & Mean_RJV & Arr_RJV & Std_RJV & Pmean & PArr & PStd & & & Adj. $R^{2}$ \\
\hline \multirow[t]{2}{*}{600276} & 0.009 & -1.856 & 0.122 & $4.901^{*}$ & $4.206^{*}$ & $-0.117^{*}$ & -9.39 & & & 0.064 \\
\hline & $C$ & Mean_RJV & Arr_RJV & Std_RJV & Pmean & PArr & PStd & Std $*$ Arr & Mean $*$ Arr & Adj. $R^{2}$ \\
\hline \multirow[t]{2}{*}{600276} & 0.025 & -1.484 & 0.03 & -3.703 & $4.598^{* *}$ & $-0.121^{*}$ & -10.859 & $42.980^{* *}$ & -2.751 & 0.148 \\
\hline & $C$ & Size_RJV & Arr_RJV & Std_RJV & & & & & & Adj. $R^{2}$ \\
\hline \multirow[t]{2}{*}{600377} & $0.115^{* * *}$ & $0.977^{*}$ & $-0.760^{* *}$ & -9.494 & & & & & & 0.047 \\
\hline & $C$ & Size_RJV & Arr_RJV & Std_RJV & Psize & PArr & PStd & & & Adj. $R^{2}$ \\
\hline \multirow[t]{2}{*}{600377} & -0.04 & $6.024^{* *}$ & -0.02 & $-12.957^{* *}$ & 5.045 & -0.042 & $-33.608^{* *}$ & & & 0.113 \\
\hline & $C$ & Size_RJV & Arr_RJV & Std_RJV & Psize & PArr & PStd & Std $*$ Arr & Size $*$ Arr & Adj. $R^{2}$ \\
\hline \multirow[t]{2}{*}{600377} & 0.055 & -0.711 & -0.268 & $22.229^{*}$ & $0.247^{*}$ & -0.043 & $-16.372^{* *}$ & $-141.272^{*}$ & $5.712^{*}$ & 0.115 \\
\hline & $C$ & Mean_RJV & Arr_RJV & Std_RJV & & & & & & Adj. $R^{2}$ \\
\hline \multirow[t]{2}{*}{600079} & -0.015 & $5.303^{* *}$ & -0.181 & $-11.173^{*}$ & & & & & & 0.073 \\
\hline & $C$ & Mean_RJV & Arr_RJV & Std_RJV & Pmean & PArr & PStd & & & Adj. $R^{2}$ \\
\hline \multirow[t]{2}{*}{600079} & -0.04 & $6.024^{* *}$ & -0.02 & $-12.957^{* *}$ & 5.045 & -0.042 & $-33.608^{* *}$ & & & 0.112 \\
\hline & $C$ & Mean_RJV & Arr_RJV & Std_RJV & Pmean & PArr & PStd & Std $*$ Arr & Mean $*$ Arr & Adj. $R^{2}$ \\
\hline \multirow[t]{2}{*}{600079} & $-0.116^{*}$ & $9.884^{* *}$ & $0.504^{*}$ & -2.751 & 4.86 & -0.063 & $-27.503^{*}$ & -34.662 & -27.183 & 0.146 \\
\hline & $C$ & Size_RJV & Arr_RJV & Std_RJV & & & & & & Adj. $R^{2}$ \\
\hline \multirow[t]{2}{*}{601006} & -0.004 & 0.177 & 0.110 & $-9.650^{*}$ & & & & & & 0.052 \\
\hline & $C$ & Size_RJV & Arr_RJV & Std_RJV & Psize & PArr & PStd & & & Adj. $R^{2}$ \\
\hline \multirow[t]{2}{*}{601006} & 0.015 & 0.358 & 0.067 & $-7.748^{*}$ & 0.188 & -0.071 & -12.002 & & & 0.053 \\
\hline & C & Size_RJV & Arr_RJV & Std_RJV & Pmean & PArr & PStd & Std $*$ Arr & Size $*$ Arr & Adj. $R^{2}$ \\
\hline \multirow[t]{2}{*}{601006} & 0.031 & 0.002 & 0.020 & -14.181 & 0.192 & -0.082 & -9.975 & 40.557 & 0.393 & 0.044 \\
\hline & C & Size_RJV & Arr_RJV & Std_RJV & & & & & & Adj. $R^{2}$ \\
\hline \multirow[t]{2}{*}{600748} & 0.049 & -0.004 & -0.178 & 0.717 & & & & & & - \\
\hline & $C$ & Size_RJV & Arr_RJV & Std_RJV & Psize & PArr & PStd & & & Adj. $R^{2}$ \\
\hline \multirow[t]{2}{*}{600748} & $0.111^{* *}$ & 0.536 & -0.187 & -2.107 & $0.642^{* *}$ & -0.253 & $-47.805^{* * *}$ & & & 0.101 \\
\hline & $C$ & Size_RJV & Arr_RJV & Std_RJV & Psize & PArr & PStd & Std $*$ Arr & Size $*$ Arr & Adj. $R^{2}$ \\
\hline 600748 & $0.119^{*}$ & -0.019 & -0.226 & 9.983 & $0.608^{* *}$ & -0.225 & $-47.241^{* * *}$ & -66.184 & 2.291 & 0.087 \\
\hline
\end{tabular}

researches on what information is contained in the jump components.

\section{Appendix}

Tables 13, 14, and 15 show the descriptive statistics of individual-based portfolio 3 to portfolio 5 and individual stock, respectively. Figure 5 shows the time series of individual stock's jump components.

We forecast one-month-ahead stock return using the following:

$$
\begin{aligned}
& r_{i, m+1}=C+\beta_{i, \text { Size }} \text { Size } \_R J V_{m}+\beta_{i, \text { Std }} \operatorname{Std}_{-} \mathrm{RJV}_{m} \\
& +\beta_{i, \mathrm{Arr}} \mathrm{Arr} \_\mathrm{RJV} \mathrm{V}_{t}+\zeta_{M, m+1} \text {, }
\end{aligned}
$$

$$
\begin{aligned}
& r_{i, m+1}=C+\beta_{i, \text { Size }} \text { Size_RJV }_{m}+\beta_{i, \text { Std }} \text { Std_RJV }_{m} \\
& +\beta_{i, \text { Arr }} \text { Arr_RJV }{ }_{m}+\beta_{P, \text { Size }} P \text { Size_RJV } m
\end{aligned}
$$

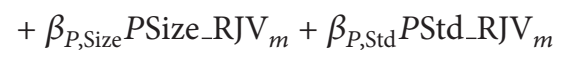

$$
\begin{aligned}
& +\zeta_{M, t+1} \\
& r_{i, m+1}=C+\beta_{i, \text { Size }} \text { Size_RJV }_{m} \\
& +\beta_{i, \text { Std }} \text { Std_RJV }_{m}+\beta_{i, \text { Arr }} \text { Arr_RJV }_{m} \\
& +\gamma_{i, \text { size_Arr }} \text { Size_RJV } V_{m} * \text { Arr_RJV }{ }_{m} \\
& +\gamma_{i, \text { std_Arr }} \text { Std_RJV }{ }_{m} * \text { Arr_RJV }{ }_{m}
\end{aligned}
$$



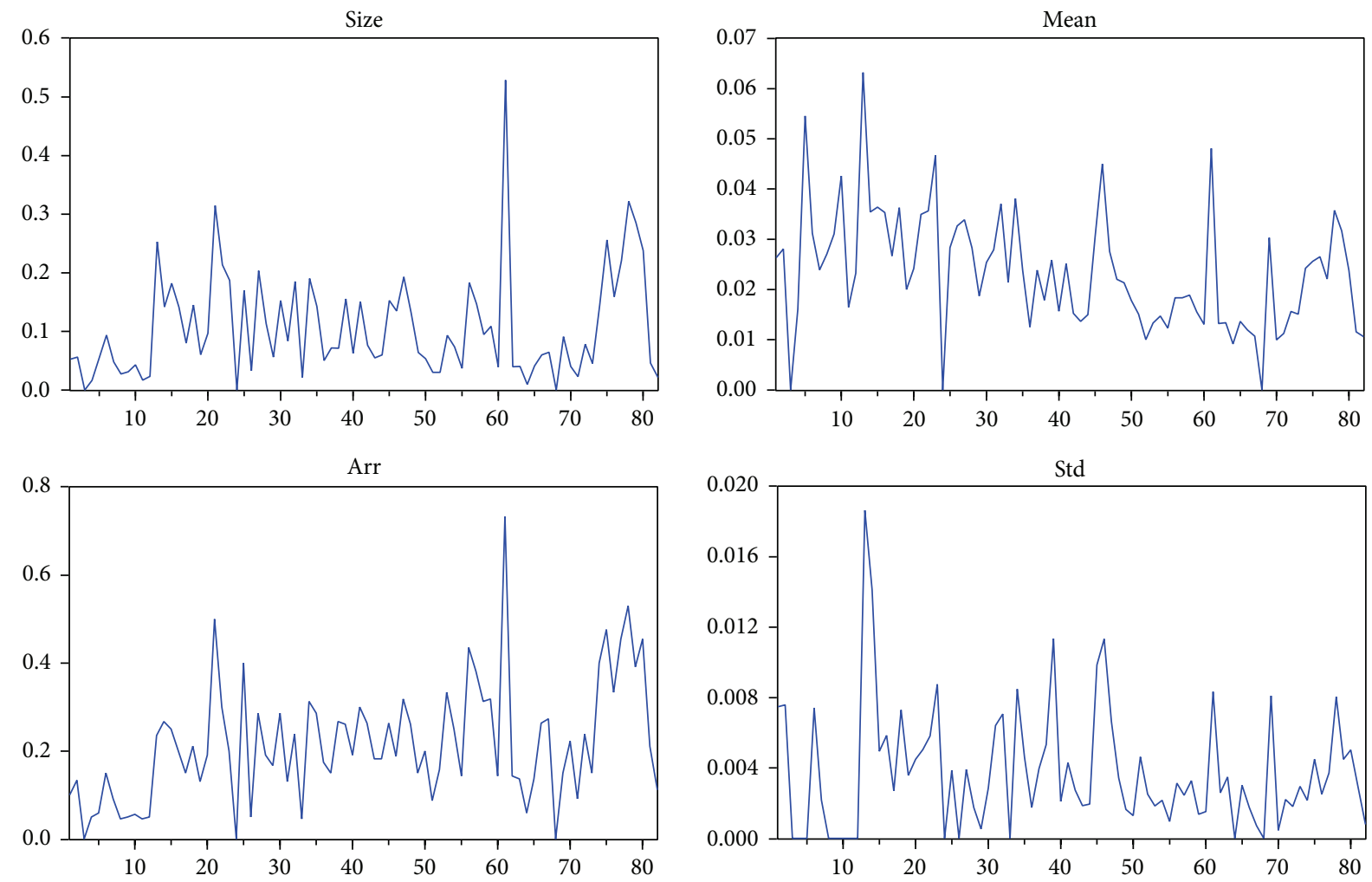

FIGURE 5: Time series characteristic of individual stock.

$$
\begin{aligned}
& +\beta_{P, \text { Size }} P \text { Size_RJV } \\
& +{ }_{m}+P \text { Std_RJV } \\
& +\beta_{P, \text { Arr }} P \text { Arr_RJV } \\
& m
\end{aligned}
$$

\section{Conflict of Interests}

The authors declare that there is no conflict of interests regarding the publication of this paper.

\section{Acknowledgment}

This work was partly supported by National Science Foundation of China (Grant no. 71071132).

\section{References}

[1] E. F. Fama and K. R. French, "The cross-section of expected stock returns," The Journal of Financial, vol. 47, no. 2, pp. 427465, 1992.

[2] E. F. Fama and K. R. French, "Common risk factors in the returns on stocks and bonds," Journal of Financial Economics, vol. 33, no. 1, pp. 3-56, 1993.

[3] C. R. Harvey and A. Siddique, "Conditional skewness in asset pricing tests," The Journal of Finance, vol. 6, no. 3, pp. 1263-1295, 2000.

[4] F. Wen and X. Yang, "Skewness of return distribution and coefficient of risk premium," Journal of Systems Science and Complexity, vol. 22, no. 3, pp. 360-371, 2009.
[5] R. C. Merton, "A simple model of capital market equilibrium with incomplete information," The Journal of Finance, vol. 42, no. 3, pp. 483-510, 1987.

[6] A. Ang, R. Hodrick, Y. Xing, and X. Zhang, "High idiosyncratic volatility and low returns: international and further U.S. evidence," Working Paper, Columbia Univerity, 2006.

[7] H. Guo and S. Robert, "Idiosyncratic volatility, stock market volatility, and expected stock returns," Journal of Business \& Economic Statistics, vol. 24, no. 1, pp. 43-56, 2006.

[8] H. Guo and S. Robert, "Average idiosyncratic volatility in G7 countries," The Review of Financial Studies, vol. 21, no. 3, pp. 1259-1296, 2008.

[9] J. Y. Campbell, M. Lettau, B. G. Malkiel, and Y. Xu, "Have individual stocks become more volatile? An empirical exploration of idiosyncratic risk," The Journal of Finance, vol. 56, no. 1, pp. $1-43,2001$.

[10] T. G. Andersen, T. Bollerslev, F. X. Diebold, and P. Labys, "The distribution of realized exchange rate volatility," Journal of the American Statistical Association, vol. 96, no. 453, pp. 42-55, 2001.

[11] T. G. Andersen, T. Bollerslev, F. Diebold, and H. Ebens, "The distribution of realized stock return volatility," Journal of Financial Economics, vol. 61, no. 1, pp. 43-76, 2001.

[12] S. J. Koopman, B. Jungbacker, and E. Hol, "Forecasting daily variability of the S\&P 100 stock index using historical, realised and implied volatility measurements," Journal of Empirical Finance, vol. 12, no. 3, pp. 445-475, 2005.

[13] F. Corsi, "A simple approximate long-memory model of realized volatility," Journal of Financial Econometrics, vol. 7, no. 2, pp. 174-196, 2009. 
[14] T. G. Andersen, T. Bollerslev, and F. X. Diebold, "Roughing it up: including jump components in the measurement, modeling, and forecasting of return volatility," The Review of Economics and Statistics, vol. 89, no. 4, pp. 701-720, 2007.

[15] T. G. Andersen, T. Bollerslev, and X. Huang, "A reduced form framework for modeling volatility of speculative prices based on realized variation measures," Journal of Econometrics, vol. 160, no. 1, pp. 176-189, 2011.

[16] F. Wen and Z. Liu, "A copula-based correlation measure and its application in chinese stock market," International Journal of Information Technology \& Decision Making, vol. 8, no. 4, pp. 787-801, 2009.

[17] C. Huang, X. Gong, X. Chen, and F. Wen, "Measuring and forecasting volatility in Chinese stock market using HAR-CJM model," Abstract and Applied Analysis, vol. 2013, Article ID 143194, 13 pages, 2013.

[18] C. Huang, C. Peng, X. Chen, and F. Wen, "Dynamics analysis of a class of delayed economic model," Abstract and Applied Analysis, vol. 2013, Article ID 962738, 12 pages, 2013.

[19] T. Adrian and J. Rosenberg, "Stock returns and volatility: pricing the short-run and long-run components of market risk," The Journal of Finance, vol. 63, no. 6, pp. 2997-3030, 2008.

[20] B. Kelly and H. Jiang, "Tail Risk and Asset Prices," Working Paper no. 19375, The National Bureau of Economic Research, 2013.

[21] R. Bansal and A. Yaron, "Risks for the long run: a potential resolution of asset pricing puzzles," The Journal of Finance, vol. 59, no. 4, pp. 1481-1509, 2004.

[22] T. A. Rietz, "The equity risk premium a solution," Journal of Monetary Economics, vol. 22, no. 1, pp. 117-131, 1988.

[23] R. Barro, "Rare disasters and asset markets in the twentieth century," Quarterly Journal of Economics, vol. 121, no. 3, pp. 823866, 2006.

[24] X. Gabaix, "Variable rare disasters: an exactly solved framework for ten puzzles in macro-finance," Quarterly Journal of Economics, vol. 127, no. 2, pp. 645-700, 2012.

[25] J. A. Wachter, "Can time-varying risk of rare disasters explain aggregate stock market volatility," The Journal of Finance, vol. 63, no. 3, pp. 987-1035, 2013.

[26] T. Bollerslev, M. Gibson, and H. Zhou, "Dynamic estimation of volatility risk premia and investor risk aversion from optionimplied and realized volatilities," Journal of Econometrics, vol. 160, no. 1, pp. 235-245, 2011.

[27] T. Bollerslev, V. Todorov, and S. Z. Li, "Jump tails, extreme dependencies, and the distribution of stock returns," Journal of Econometrics, vol. 172, no. 2, pp. 307-324, 2013.

[28] E. Fama and K. French, "Multifactor explanations of asset pricing anomalies," The Journal of Finance, vol. 51, no. 1, pp. 5584, 1996.

[29] G. Tauchen and H. Zhou, "Realized jumps on financial markets and predicting credit spreads," Journal of Econometrics, vol. 160, no. 1, pp. 102-118, 2011.

[30] T. Bollerslev, T. H. Law, and G. Tauchen, "Risk, jumps, and diversification," Journal of Econometrics, vol. 144, no. 1, pp. 234256, 2008.

[31] G. Qin, C. Huang, Y. Xie, and F. Wen, "Asymptotic behavior for third-order quasi-linear differential equations," Advances in Differential Equations, vol. 2013, article 305, pp. 1-8, 2013.

[32] A. R. Jarrow and E. R. Rosenfeld, "Jump risks and the intertemporal captial asset pricing model," The Journal of Business, vol. 57, no. 3, pp. 337-351, 1984.
[33] T. G. Andersen and T. Bollerslev, "Answering the skeptics: yes, standard volatility models do provide accurate forecasts," International Economic Review, vol. 39, no. 4, pp. 885-905, 1998.

[34] O. Barndorff-Nielsen and N. Shephard, "Econometric analysis of realized volatility and its use in estimating stochastic volatility models," Journal of the Royal Statistical Society B: Statistical Methodology, vol. 64, no. 2, pp. 253-280, 2002.

[35] O. Barndorff-Nielsen and N. Shephard, "Estimating quadratic variation using realized variance," Journal of Applied Econometrics, vol. 17, no. 5, pp. 457-477, 2002.

[36] N. Meddahi, "A theoretical comparison between integrated and realized volatility," Journal of Applied Econometrics, vol. 17, no. 5, pp. 479-508, 2002.

[37] O. E. Barndorff-Nielsen and N. Shephard, "Power and bipower variation with stochastic volatility and jumps," Journal of Financial Econometrics, vol. 2, no. 1, pp. 1-37, 2004.

[38] O. E. Barndorff-Nielsen and N. Shephard, "Econometrics of testing for jumps in financial economics using bipower variation," Journal of Financial Econometrics, vol. 4, no. 1, pp. 1-30, 2006.

[39] T. G. Andersen, T. Bollerslev, and F. Diebold, "Some like it smooth, and some like it rough: untangling continuous and jump components in measuring, modeling, and forecasting asset return volatility," Working Paper, Department of Economics, University of Pennsylvania, 2003.

[40] X. Huang and G. Tauchen, "The relative contribution of jumps to total price variance," Journal of Financial Econometrics, vol. 3, no. 4, pp. 456-499, 2005.

[41] R. Merton, "Option pricing when underlying stock returns are discontinuous," Journal of Financial Economics, vol. 3, no. 1-2, pp. 125-144, 1976. 


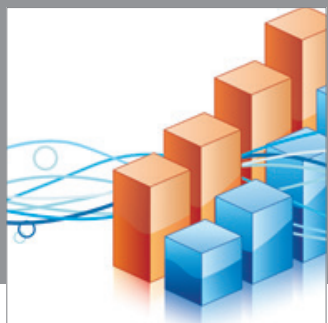

Advances in

Operations Research

mansans

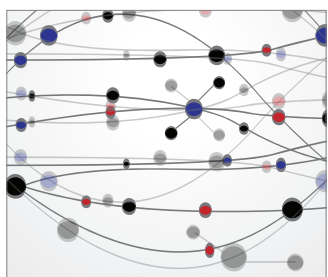

The Scientific World Journal
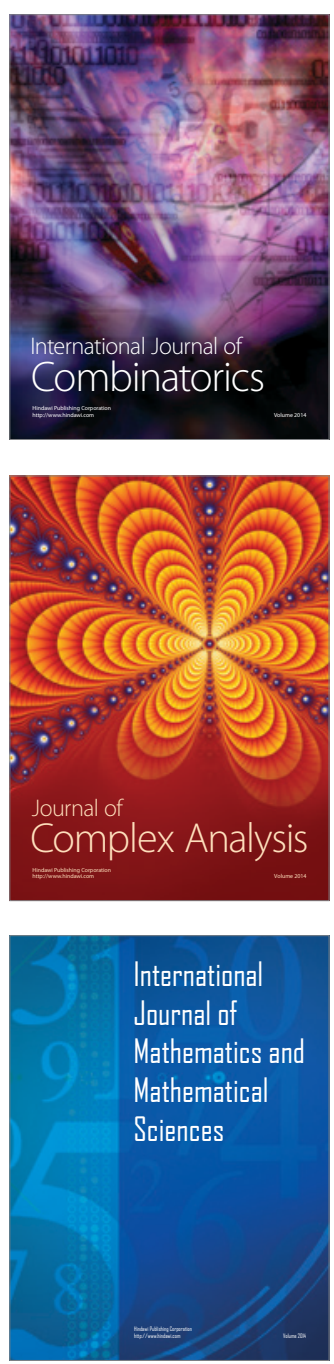
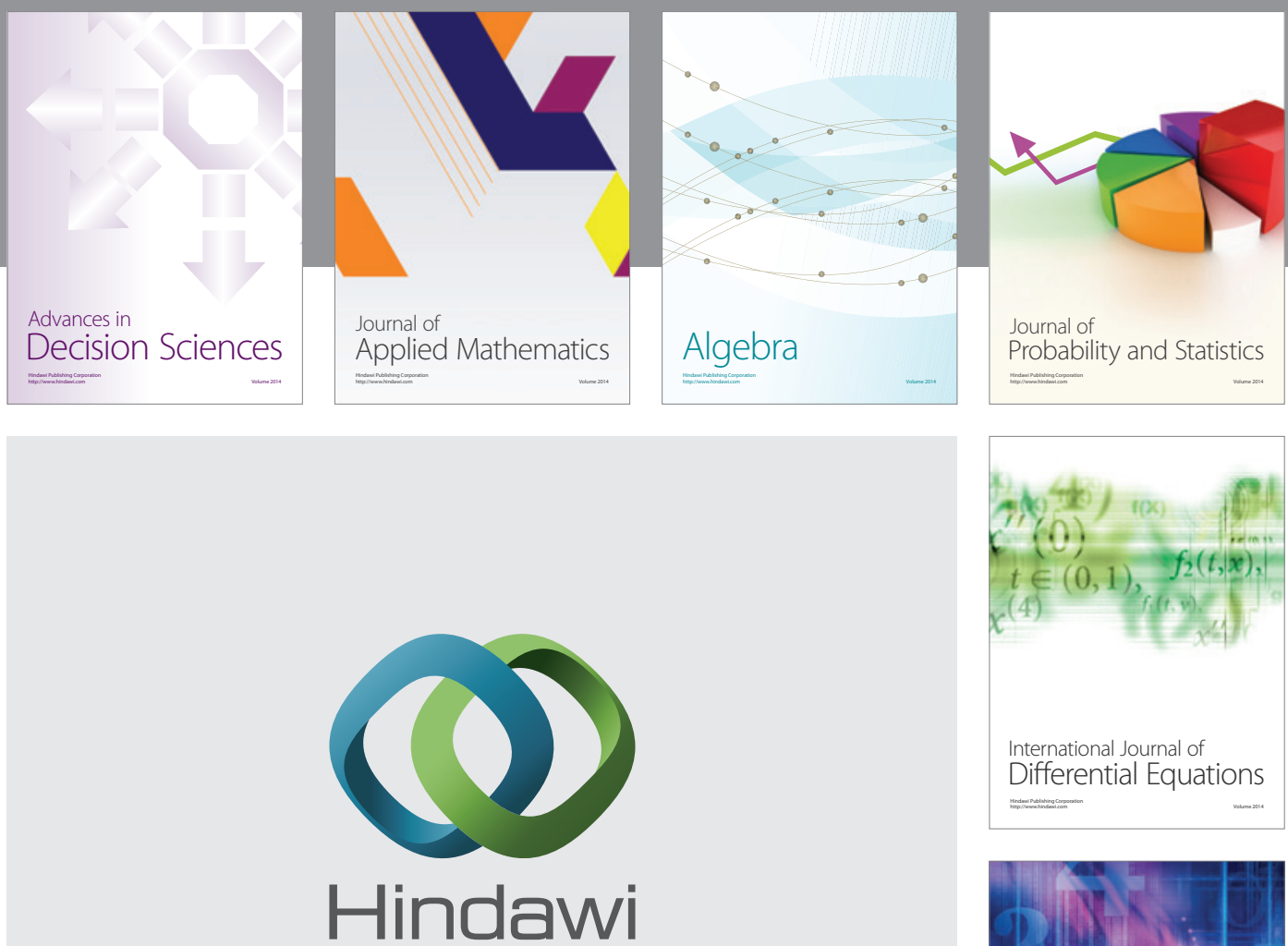

Submit your manuscripts at http://www.hindawi.com
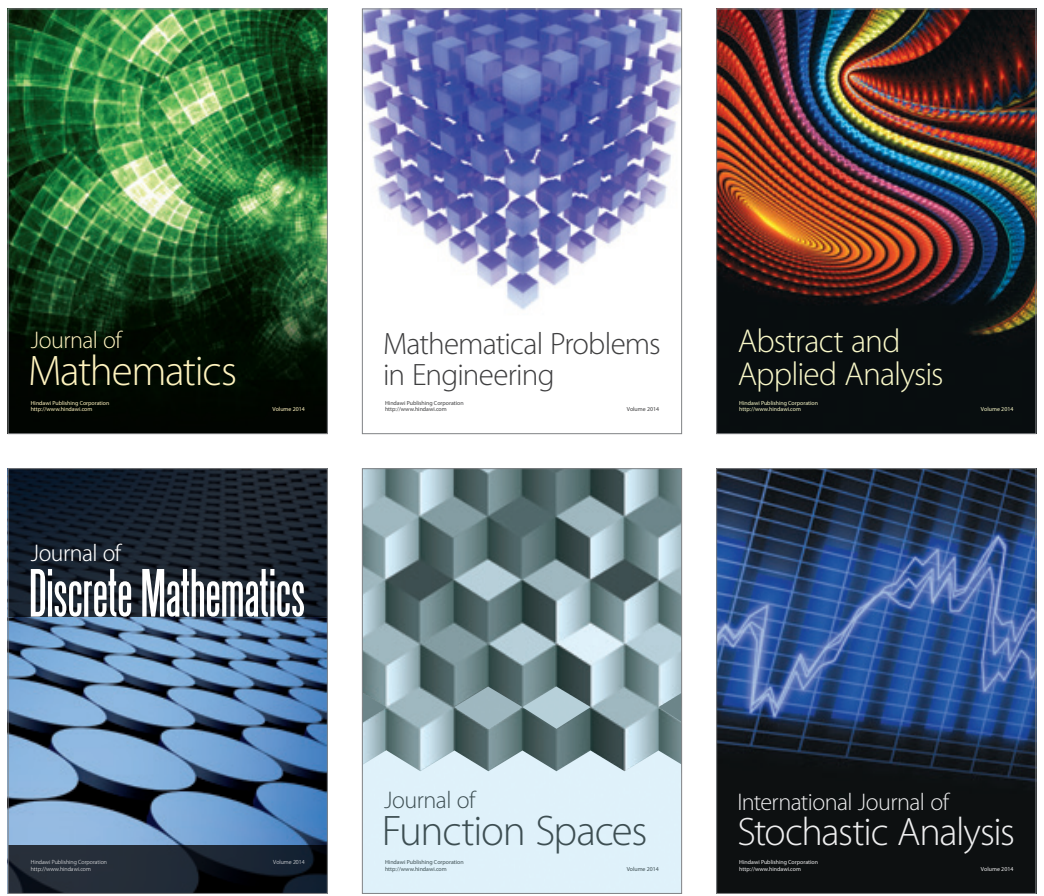

Journal of

Function Spaces

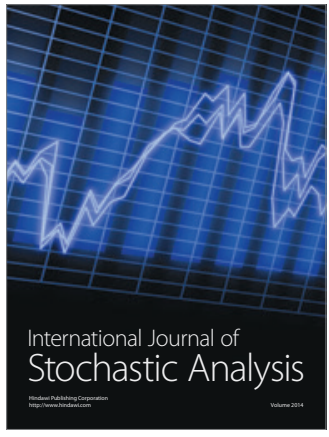

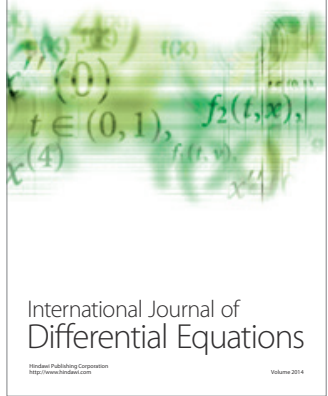
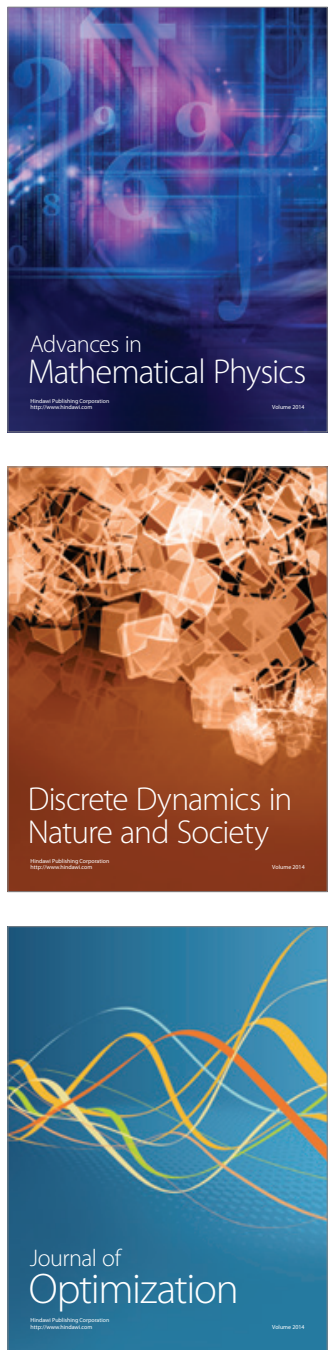